\section{References}

1. Apostolakis E, Shuhaiber JH. The surgical management of giant left atrium. Eur J Cardiothorac Surg. 2008;33:182-90.

2. Rajakaruna C, Mhandu P, Ghosh-Dastidar M, Desai J. Giant left atrium secondary to severe mixed mitral valve pathology. Eur $J$ Cardiothorac Surg. 2007;32:932.
3. Kawazoe K, Beppu S, Takahara Y, Nakajima N, Tanaka K, Ichihashi K, et al. Surgical treatment of giant left atrium combined with mitral valve disease. J Thorac Cardiovasc Surg. 1983;85:885-92.

4. Boldyrev SY, Antipov GN, Porhanov VA. First experience of cardiac autotransplantation for giant left atrium treatment. Interact Cardiovasc Thorac Surg. 2009;8:173-5.

\title{
Effective mechanical cardiac support in a child in the absence of a mitral valve
}

\author{
Matteo Trezzi, MD, ${ }^{a}$ Scott M. Bradley, MD, ${ }^{a}$ Andrew J. Savage, MD, ${ }^{b}$ and Minoo N. Kavarana, MD, ${ }^{a}$ \\ Charleston, SC
}

Although mechanical support for adult heart failure is well established, the options have been limited for children. In particular, little is known about the treatment of children with mechanical mitral valve prostheses undergoing ventricular assist device (VAD) implantation. The current recommendations for adult patients are to leave in place a well-functioning prosthesis while maintaining a higher international normalized ratio postoperatively. ${ }^{1}$ If significant stenosis is present, the recommendation is to perform bioprosthetic valve replacement. ${ }^{2}$ For patients undergoing VAD implantation for complex congenital heart disease, this could significantly increase the duration and morbidity of the procedure.

\section{CASE REPORT}

An 11-year-old girl presented with severe biventricular dysfunction, worsening dyspnea at rest, and a cough with hemoptysis. She had previously undergone neonatal coarctation repair, pulmonary artery banding, and subsequent repair of a complete atrioventricular septal defect and pulmonary artery debanding performed at an outside facility. Over time, she developed severe mitral valve regurgitation, which led to valve repair and, subsequently, replacement with a 21-mm mechanical prosthesis. The latter was complicated by heart block requiring a permanent epicardial pacemaker. Gradually,

\footnotetext{
From the Pediatric Cardiothoracic Surgery Section, ${ }^{a}$ Division of Cardiothoracic Surgery, and Division of Pediatric Cardiology, ${ }^{\mathrm{b}}$ Medical University of South Carolina, Charleston, SC.

Disclosures: Authors have nothing to disclose with regard to commercial support. Received for publication July 10, 2013; revisions received July 28, 2013; accepted for publication Aug 1, 2013; available ahead of print Sept 25, 2013.

Address for reprints: Minoo N. Kavarana, MD, Pediatric Cardiothoracic Surgery Section, Division of Cardiothoracic Surgery, Medical University of South Carolina, 96 Jonathan Lucas St, CSB 424/MSC 613, Charleston, SC 29425-6130 (E-mail: kavarana@musc.edu).

J Thorac Cardiovasc Surg 2013;146:e61-2

$0022-5223 / \$ 36.00$

Copyright (C) 2013 by The American Association for Thoracic Surgery

http://dx.doi.org/10.1016/j.jtcvs.2013.08.002
}

she developed worsening prosthetic mitral stenosis. Her echocardiogram showed a mean mitral gradient of 14 $\mathrm{mm} \mathrm{Hg}$, dilated left and right ventricles with severely depressed function, moderate aortic insufficiency, and severe tricuspid valve regurgitation. During a brief period of evaluation, her hemodynamics deteriorated, with evidence of progressive end-organ dysfunction despite maximal medical therapy. The decision was made to urgently institute mechanical support as a bridge to transplantation.

Cardiopulmonary bypass was established through groin cannulation, and a reoperative median sternotomy was performed. The adhesions were significant, and the left ventricle (LV) was severely dilated, occupying the entire left hemithorax. After cardioplegic arrest, left atriotomy was performed. The mechanical mitral valve prosthesis had extensive pannus overgrowth, with a very small effective orifice area. We decided that excision of this stenotic prosthetic valve would provide the simplest solution. With knowledge of a previous report of this unsuccessful strategy using LV apical cannulation, ${ }^{3}$ we decided to

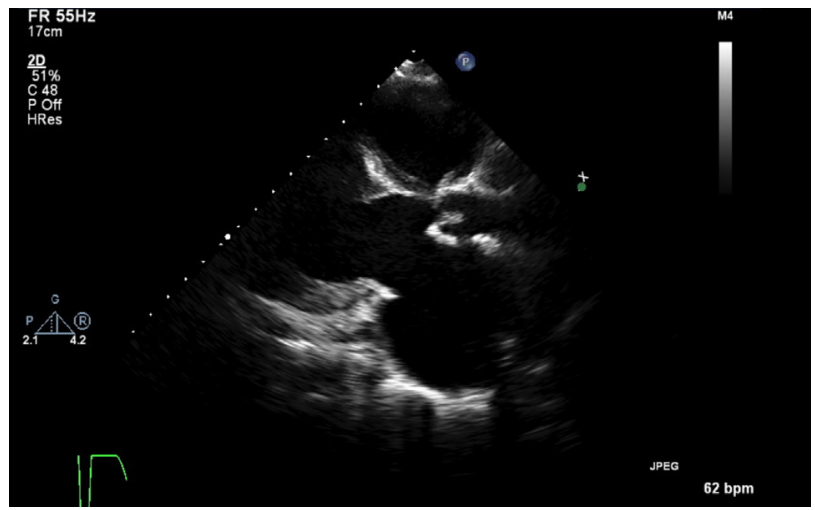

FIGURE 1. Parasternal, 2-dimensional, long-axis view showing absent mitral valve and thickened aortic valve cusps after repair. 


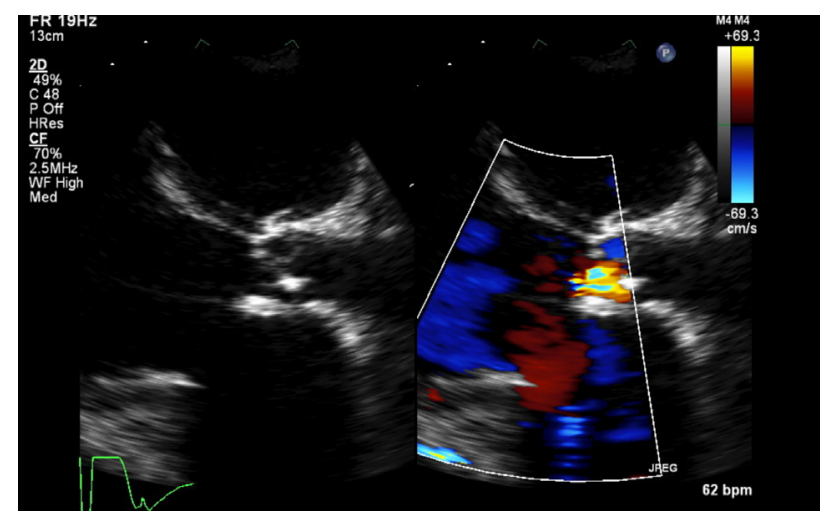

FIGURE 2. Parasternal, color Doppler, long-axis view showing free mitral regurgitation and trivial aortic insufficiency.

place the inflow cannula in the left atrium to facilitate direct left atrial (LA) drainage. The 12-mm Berlin Heart silicone inflow cannula had a layer of Dacron velour over the midportion and a sewing ring that was incorporated into the left atriotomy with running 4-0 polypropylene suture to maintain the cannula orientation at a right angle to the LA free wall. The aortic valve was repaired with a Park's stitch. ${ }^{4}$ The aortic outflow cannula and the right atrial and pulmonary artery VAD cannulas were implanted in a standard fashion. Biventricular assist device support (Berlin Heart EXCOR, The Woodlands, Tex) was then established, with 50-mL left and right pumps at a rate of 90 beats $/ \mathrm{min}$, and the patient was weaned off cardiopulmonary bypass. Transesophageal echocardiography was used to optimize LV decompression by adjusting the left VAD (LVAD) negative diastolic pressures and percentage of diastole. Postoperatively, her hemodynamics were excellent, with a low central venous pressure. Chest radiography showed resolution of the preoperative pulmonary edema. Postoperative echocardiograms showed free atrioventricular valve regurgitation and no aortic insufficiency (Figures 1 and 2). At 2 weeks postoperatively, she underwent cardiac transplantation, had an uneventful postoperative course, and was discharged home.

\section{DISCUSSION}

Mechanical support in the pediatric population remains a challenge because the options for small children are limited. ${ }^{5}$ Furthermore, children with complicated congenital heart defects are now surviving high-risk surgical interventions with residual defects and ventricular dysfunction. A previous report of prosthesis excision in 2 adults on LVAD support resulted in high LA pressures, necessitating bioprosthetic valve replacement. Intuitively, the increase in LA pressure was related to the flow of blood into the left atrium during LVAD systole. During active LVAD diastole in pulsatile devices, the negative pressure exerted within the LV prevents LA hypertension. Pannus excision while leaving the prosthesis in place was considered, just as was tissue valve replacement. However, the small annulus would have resulted in residual moderate to severe stenosis. Furthermore, minimizing the crossclamp time was important because of this highly complex and lengthy procedure. We, therefore, elected to remove the mitral prosthesis and place the inflow cannula into the left atrium rather than in the LV. This is the first successful report of biventricular VAD support in a child, with excision of the prosthetic mitral valve, in the setting of severe prosthetic valve stenosis. This surgical approach minimized the crossclamp time and significantly simplified the operation and the postoperative anticoagulation therapy. It remains unknown whether this strategy would be successful in the setting of continuous flow devices and LV apical cannulation. However, with a pulsatile LVAD and LA cannulation, the present report has demonstrated excellent LV decompression, no LA hypertension, and successful biventricular VAD support as a bridge to heart transplantation.

\section{References}

1. Schweiger M, Stepanenko A, Vierecke J, Drews T, Potapov E, Hetzer R, et al. Preexisting mitral valve prosthesis in patients undergoing left ventricular assist device implantation. Artif Organs. 2012;36:49-53.

2. Feldman D, Pamboukian SV, Teuteberg JJ, Birks E, Lietz K, Moore SA, et al. The 2013 International Society for Heart and Lung Transplantation Guidelines for mechanical circulatory support: executive summary. J Heart Lung Transplant. 2013;32:157-87.

3. McCarthy PM, Smedira N. Implantable LVAD insertion in patients with previous heart surgery. J Heart Lung Transplant. 2000;19:95-100.

4. Park SJ, Liao KK, Segurola R, Madhu KP, Miller LW. Management of aortic insufficiency in patients with left ventricular assist devices: a simple coaptation stitch method (Park's stitch). J Thorac Cardiovasc Surg. 2004; 127:264-6.

5. Gandhi SK, Huddleston CB, Blazer DT, Epstein DJ, Boschert TA, Canter CE. Biventricular assist devices as a bridge to heart transplantation in small children. Circulation. 2008;118:S89-93. 